\title{
A comprehensive review of nongenetic prognostic and predictive factors influencing the heterogeneity of outcomes in advanced non-small-cell lung cancer
}

\author{
This article was published in the following Dove Press journal: \\ Cancer Management and Research \\ 23 October 2014 \\ Number of times this article has been viewed
}

\author{
Gebra Cuyún Carter ${ }^{\prime}$ \\ Amy M Barrett ${ }^{2}$ \\ James A Kaye ${ }^{3}$ \\ Astra M Liepa' \\ Katherine B Winfree' \\ William J John' \\ 'Eli Lilly and Company, Indianapolis, \\ IN, USA; ${ }^{2}$ RTI Health Solutions, \\ Research Triangle Park, NC, USA; ${ }^{3}$ RTI \\ Health Solutions, Waltham, MA, USA
}

Correspondence: Gebra Cuyún Carter Global Health Outcomes, Oncology, Eli Lilly and Company, 893 S Delaware Street, Indianapolis, IN 46285, USA

Tel +l 3176559943

Fax +I 3172775912

Email cuyun_carter_gebra@lilly.com

\begin{abstract}
While there have been advances in treatment options for those with advanced non-small-cell lung cancer, unmet medical needs remain, partly due to the heterogeneity of treatment effect observed among patients. The goals of this literature review were to provide updated information to complement past reviews and to identify a comprehensive set of nongenetic prognostic and predictive baseline factors that may account for heterogeneity of outcomes in advanced non-small-cell lung cancer. A review of the literature between 2000 and 2010 was performed using PubMed, Embase, and Cochrane Library. All relevant studies that met the inclusion criteria were selected and data elements were abstracted. A classification system was developed to evaluate the level of evidence for each study. A total of 54 studies were selected for inclusion. Patient-related factors (eg, performance status, sex, and age) were the most extensively researched nongenetic prognostic factors, followed by disease stage and histology. Moderately researched prognostic factors were weight-related variables and number or site of metastases, and the least studied were comorbidities, previous therapy, smoking status, hemoglobin level, and health-related quality of life/symptom severity. The prognostic factors with the most consistently demonstrated associations with outcomes were performance status, number or site of metastases, previous therapy, smoking status, and health-related quality of life. Of the small number of studies that assessed predictive factors, those that were found to be significantly predictive of outcomes were performance status, age, disease stage, previous therapy, race, smoking status, sex, and histology. These results provide a comprehensive overview of nongenetic prognostic and predictive factors assessed in advanced non-small-cell lung cancer over the last decade. This information can be used to inform the design of future clinical trials by suggesting additional subgroups based on nongenetic factors that may be analyzed to further investigate potential prognostic and predictive factors.
\end{abstract}

Keywords: NSCLC, heterogeneity, treatment outcome, review

\section{Introduction}

Lung cancer has the highest mortality rate of any cancer type worldwide. ${ }^{1}$ While there have been advances in therapeutic options for those with advanced (stage III/IV) nonsmall-cell lung cancer (NSCLC), particularly for subgroups of patients who qualify for treatment with newer targeted agents, a significant unmet medical need remains. There have been small gains in NSCLC survival rates; however, the significance of these gains and the benefits to patients with a variety of characteristics are unclear. ${ }^{2,3}$

Previous research identified several elements, including age, sex, comorbidities, and health care resource utilization, which are associated with differential treatment 
response and/or outcomes in NSCLC. ${ }^{4}$ Prognostic factors are those variables that are associated with a clinical outcome (prognosis) that is independent of a given therapy. ${ }^{5,6}$ Prognostic factor information is important for the stratification of patients in clinical trial protocols and for the individualization of a patient care plan. ${ }^{4}$ By contrast, predictive factors provide a probability that a patient will respond more favorably to a particular therapy. Predictive factors are important to consider when selecting patients likely to respond to a particular therapy and when evaluating multiple treatment options that are available for a particular patient., ${ }^{4,6}$

Heterogeneity of treatment effect (HTE) describes the differences in treatment outcomes observed within and outside clinical trials. ${ }^{7,8}$ Some patients will benefit more or less than the average patients reported in the clinical trial literature; understanding HTE is necessary to individualize treatment and optimize patient outcomes. ${ }^{9}$ Prognostic and predictive factors influence $\mathrm{HTE}^{\cdot 5,6}$ therefore, identifying these factors and accounting for HTE in the development of new therapies will provide valuable information to evidence-based decision makers, while potentially improving clinical outcomes and health-related quality of life (HRQoL) for patients.

While much of the current research in NSCLC has focused on the identification of genetic prognostic and predictive factors, there is also value in understanding nongenetic factors or patient-related factors that are associated with HTE but are not related to known genetic markers. In the recent past, nongenetic factors have identified subgroups that have later been established as clinical correlates of genetic markers. For example, early studies found that subgroups of patients with NSCLC who were female, Asian, and nonsmokers or former light smokers and had tumors with adenocarcinoma histology were more likely to respond to epidermal growth factor receptor (EGFR) inhibitors than were patients without these characteristics. ${ }^{10}$ It was later determined that patient subgroups whose tumors had activating EGFR mutations were the most responsive to EGFR inhibitors and that the clinical factors identified to predict response were associated with the target gene mutations in the NSCLC population. ${ }^{10}$ This early characterization of patients helped to predict which patients might benefit more from EGFR inhibitors before the underlying genetic marker was identified.

In general, prognostic factors for all types of advancedstage cancer include performance status (PS), clinical signs and symptoms (eg, related to anorexia, weight loss, dyspnea, and dysphagia), and biological factors (eg, leukocytosis, lymphocytopenia, and C-reactive protein). ${ }^{11}$ A 2002 literature review identified 169 tumor- or patient-related prognostic factors, and identified those prognostic factors for patients with advanced NSCLC that were essential for decision making (ie, stage of disease, hypercalcemia, superior vena cava obstruction, weight loss, and PS). ${ }^{12}$ New and emerging factors at the time of the 2002 review included items such as HRQoL, marital status, depressed mood, and various molecular biological markers. ${ }^{12}$ Brundage et al noted that individual studies in the review were repeatedly underpowered and narrowly focused and had highly variable results. ${ }^{12}$

In addition, a 2003 review identified prognostic factors that should be used when selecting stage IV NSCLC patients for systemic chemotherapy. ${ }^{13}$ Prior chemotherapy was consistently identified as an important prognostic factor, and PS at the time of diagnosis was deemed a powerful indicator of survival. ${ }^{13}$ Disease stage is one of the most well-established prognostic factors in NSCLC. ${ }^{12,13}$ Pretreatment weight loss was identified as a negative factor for survival, whereas high HRQoL scores, high levels of albumin, low levels of alkaline phosphatase, and expression of neuroendocrine markers were associated with positive outcomes. ${ }^{13}$ Histologic subtype was reported to be an unreliable prognostic factor, and age was deemed a possible indicator as some studies suggest that elderly patients with advanced NSCLC have poorer outcomes. ${ }^{13}$

The goals of this literature review were to provide updated information to complement past reviews and to focus on the identification of a comprehensive set of nongenetic prognostic and predictive baseline tumor- and patient-related factors that identify subpopulations of advanced-stage NSCLC patients with differential treatment response and outcomes.

\section{Materials and methods Search strategy}

Three key databases were used for this search: PubMed, Embase, and Cochrane Library. The database searches were limited to studies published in English between January 2000 and November 2010. Published materials from the 2010 annual meeting of the American Society of Clinical Oncology were also reviewed. Conceptually, the inclusion criteria of the search strategy focused on stage III/IV NSCLC, Phase III or IV clinical trials, observational studies, meta-analyses, and systematic reviews. The search strategy developed for PubMed and adapted for use in the other databases is presented in Table 1.

\section{Definitions}

In this review, prognostic factors were defined as tumor- or patient-related factors that provided risk information about 
Table I PubMed search strategy for heterogeneity in advanced non-small-cell lung cancer

\begin{tabular}{|c|c|}
\hline Search number & Search terms \\
\hline \multicolumn{2}{|l|}{ Disease terms } \\
\hline \multirow[t]{3}{*}{ I } & “Carcinoma, Non-Small-Cell Lung”[MeSH] AND (“stage IV”[Text Word] OR “stage III/IV”[Text \\
\hline & Word] OR “metastatic"[Text Word] OR "metastasis"[Text Word] OR "metastases"[Text Word] \\
\hline & OR “advanced”[Text Word]) \\
\hline \multicolumn{2}{|l|}{ Study types } \\
\hline \multirow[t]{4}{*}{2} & “Observational”[Text Word] OR “Cohort Studies" $[\mathrm{MeSH}]$ OR "Retrospective Studies" [MeSH] OR \\
\hline & “Cross-Sectional Studies”[MeSH] OR “Clinical Trial, Phase III”[Publication Type] OR “Clinical Trial, \\
\hline & Phase IV”[Publication Type] OR “Controlled Clinical Trial”[Publication Type] OR “Randomized \\
\hline & Controlled Trial”[Publication Type] OR “Meta-Analysis"[Publication Type] OR “systematic \\
\hline \multicolumn{2}{|c|}{ Terms related to prognostic/predictive } \\
\hline \multirow[t]{3}{*}{3} & “Prognosis"[MeSH] OR predict*[Text Word $]$ OR prognos*[Text Word $]$ OR “interaction" $[$ Text \\
\hline & Word] OR "multivariate" [Text Word] OR heterogen*[Text Word] OR mediat*[Text Word] OR \\
\hline & moderat*[Text Word $]$ \\
\hline \multicolumn{2}{|c|}{ Exclusionary terms } \\
\hline \multirow[t]{8}{*}{4} & “Early Diagnosis”[MeSH] OR “Early Detection of Cancer”[MeSH] OR “Molecular \\
\hline & Epidemiology"[MeSH] OR “genotype"[Title] OR “gene"[Title] OR “genes"[Title] OR \\
\hline & "molecular"[Title] OR "Costs and Cost Analysis"[MeSH] OR "Economics"[MeSH] OR \\
\hline & "economics"[Subheading] OR “Cost-Benefit Analysis" [MeSH] OR "Cost of Illness"[MeSH] OR "Cost \\
\hline & Savings"[MeSH] OR "Health Care Costs"[MeSH] OR "staging"[Title] OR ("radiotherapy" [Text \\
\hline & Word] NOT “chemotherapy”[Text Word]) OR “adjuvant"[Title] OR “early-stage"[Title] OR \\
\hline & “neo-adjuvant"[Title] OR neoadjuvant"[Title] OR detect*[Title] OR “preoperative"[Title] OR "pre- \\
\hline & operative"[Title] OR ("stage I"[Text Word] NOT "stage IV"[Text Word]) OR prevent*[Title] \\
\hline \multicolumn{2}{|c|}{ Combined searches } \\
\hline 5 & (\#I AND \#2 AND \#3) NOT \#4 \\
\hline 6 & “Animals"[MeSH] NOT “Humans"[MeSH] \\
\hline \multirow[t]{2}{*}{7} & "Case Reports"[Publication Type] OR “Comment"[Publication Type] OR “Letter"[Publication Type] \\
\hline & OR “Editorial”[Publication Type] \\
\hline 8 & \#5 NOT (\#6 OR \#7) \\
\hline
\end{tabular}

Note: aSearch limited to studies published between January 2000 and November 2010.

achieving a specific clinical outcome (progression-free survival [PFS], overall survival [OS], time to progression [TTP], or response rate [RR]), independent of treatment. ${ }^{5}$ Predictive factors were defined as factors that identified patients who had a different probability of achieving a specific outcome (ie, PFS, OS, TTP, or RR) only when treated with a specific therapy. ${ }^{5}$ The direction of the association between factors and outcomes was also examined.

\section{Study classification system}

A classification system specific to studies that assessed prognostic or predictive factors was developed for this review, in order to differentiate among studies based on the rigor of the methods used to assess prognostic or predictive ability and to analyze the strength of evidence for the factors explored in these studies. Based on the classification system, all studies were assigned a qualitative evidence rating by one author that was verified by a second author. The classification system reflects that higher quality prognostic and predictive studies were those with greater internal validity (eg, data analyzed were from randomized controlled trials versus observational studies), with larger versus smaller sample sizes, and with multivariate versus univariate analyses. The clinical trial sample sizes in the classification categories were selected arbitrarily, based on the sizes of the trials in the identified studies. According to these criteria, studies were rated on a scale of one to five. The highest rating possible for a prognostic study was PROG-1 and the lowest rating was PROG-5. Meta-analyses, systematic reviews, and multiple clinical trials were assigned level one, the highest ranking. Single larger clinical trial studies ( $\mathrm{n} \geq 200$ for a two-arm study; $n \geq 300$ for a three-arm study) were assigned level two. Single smaller clinical trial studies ( $\mathrm{n}<200$ for a two-arm study; $\mathrm{n}<300$ for a three-arm study) were assigned level three. Observational studies were assigned level four. Studies with no regression model or only univariate models were assigned a level five ranking, the lowest quality ranking.

Similarly, the highest possible rating for a predictive study was PRED-1 and the lowest possible rating was PRED-5. Factor validation studies prospectively designed to assess a predictive factor were assigned level one. The presence of a formal statistical interaction test, regardless of the size or 
number of trials, was assigned level two. Analyses of clinical trial(s) with a multivariate model without a formal test of interaction were assigned level three. Analyses of observational studies with or without a formal test of interaction were assigned level four. Predictive studies with no regression model or only univariate models were assigned a level five ranking, the lowest quality ranking. If a study presented data for both prognostic and predictive factors, the study was rated separately on each scale. Only the highest ranked studies were retained for this review; therefore, those studies assigned level PROG-5 and PRED-5 ratings were excluded.

\section{Results}

All evaluated studies were retrospective analyses of randomized controlled trials or observational study data. The literature review identified 1,856 records. After duplicates were removed, there were 1,286 unique journal articles (PubMed 1,030, Embase 243, and Cochrane 13). The American Society of Clinical Oncology search identified 57 records (36 prognostic and 21 predictive factors). Of the 1,343 records that were initially identified and screened, 65 studies focused on prognostic factors or predictive factors and were reviewed and abstracted. Ultimately, only the highest ranked studies were retained; therefore, eleven studies (nine prognostic and two predictive) with the lowest ranking in the study classification system (PROG-5 and PRED-5) were excluded (Table 2). A total of 54 studies were selected for final inclusion in the literature review; 50 studies focused on prognostic factors (six of which included both prognostic and predictive factors) and four studies focused exclusively on predictive factors (Figure 1).

\section{Prognostic factors}

Prognostic factor studies are summarized in Table 3, and the directionality of evidence for the prognostic factors is presented in Figure 2.

PS was one of the most consistently explored factors. Most studies categorized PS with the Eastern Cooperative Oncology Group PS scale as PS 0/1 versus PS 2 (or PS $\geq 2$ ). The other scale used was the Karnofsky Performance Status (KPS) scale, most often categorized as KPS $<70$ versus KPS $\geq 80$. There were 49 studies that evaluated PS as a prognostic factor, with $73 \%(n=36)$ reporting a significant association. Eleven $(85 \%)$ of the 13 PROG-1 studies reported a significant association with outcomes, including tumor response or survival, as did $89 \%$ of the nine PROG- 2 studies, $82 \%$ of the eleven PROG-3 studies, and $50 \%$ of the 16 PROG- 4 studies. In the 36 studies that reported a significant association between outcomes (tumor response or survival) and PS, a better PS (lower Eastern
Table 2 Summary of study classification system

\begin{tabular}{|c|c|c|}
\hline Study rating & \# & Study types \\
\hline \multicolumn{3}{|c|}{ Prognostic studies $^{a}(n=50)$} \\
\hline PROG-I & 14 & $\begin{array}{l}\text { Retrospective analysis with multivariate } \\
\text { model of multiple clinical trials, systematic } \\
\text { review, or meta-analysis. }\end{array}$ \\
\hline PROG-2 & 9 & $\begin{array}{l}\text { Retrospective analysis with multivariate } \\
\text { model of single larger trial ( } n \geq 200 \text { for a two- } \\
\text { arm study; } n \geq 300 \text { for a three-arm study). }\end{array}$ \\
\hline PROG-3 & 11 & $\begin{array}{l}\text { Retrospective analysis with multivariate } \\
\text { model of single smaller trial ( } \mathrm{n}<200 \text { for } \\
\text { a two-arm study; } \mathrm{n}<300 \text { for a three-arm } \\
\text { study). }\end{array}$ \\
\hline PROG-4 & 16 & $\begin{array}{l}\text { Retrospective analysis with multivariate } \\
\text { model of observational study. }\end{array}$ \\
\hline \multicolumn{3}{|c|}{ Predictive studies $^{\mathrm{b}}(\mathrm{n}=4)$} \\
\hline PRED-I & 0 & $\begin{array}{l}\text { Factor validation study prospectively } \\
\text { designed to assess a predictive factor (as } \\
\text { described in Sargent et al }{ }^{5} \text { ). }\end{array}$ \\
\hline PRED-2 & 4 & $\begin{array}{l}\text { Retrospective analysis of clinical trial(s) } \\
\text { with multivariate model plus formal test of } \\
\text { interaction (including systematic review or } \\
\text { meta-analysis reporting interaction test). }\end{array}$ \\
\hline PRED-3 & 0 & $\begin{array}{l}\text { Retrospective analysis of clinical trial(s) with } \\
\text { multivariate model without formal test of } \\
\text { interaction. }\end{array}$ \\
\hline PRED-4 & 0 & $\begin{array}{l}\text { Retrospective analysis with multivariate } \\
\text { model of observational study, with or } \\
\text { without formal test of interaction. }\end{array}$ \\
\hline
\end{tabular}

Notes: PROG-I-5 and PRED-I-5 represent a rating system for prognostic and predictive studies, respectively, where one is high and five is low. ${ }^{a}$ Fifty studies focused on prognostic factors (six of which focused on both prognostic and predictive factors). Nine PROG-5 studies excluded from final analyses (no regression modeling or only a univariate model). ${ }^{b}$ Four studies focused exclusively on predictive factors. Two PRED-5 studies excluded from final analyses (no regression modeling or only a univariate model).

Abbreviation: \#, number of studies.

Cooperative Oncology Group PS score or higher KPS score) was associated with a better outcome. ${ }^{14-49}$

The majority of the studies that assessed disease stage compared stage IIIB NSCLC with stage IV. There were 38 studies that evaluated disease stage as a prognostic factor, with $55 \%(n=21)$ reporting a significant association between disease stage and response or survival. Seven (70\%) of the ten PROG-1 studies reported that disease stage is a significant prognostic factor, as did 33\% of the nine PROG-2 studies, $29 \%$ of the seven PROG-3 studies, and $75 \%$ of the 12 PROG-4 studies. In the 21 studies that reported a significant association between disease stage and response or survival, less advanced disease stage was associated with a better outcome in all studies. ${ }^{14,15,17,20-22,24,26,31,32,35,37,42-44,47,48,50-53}$

Sex was a frequently evaluated factor - there were 45 studies that assessed sex as a prognostic factor, with a total of $17(38 \%)$ studies reporting a significant finding. Six (46\%) of the 13 PROG-1 studies reported a significant association 


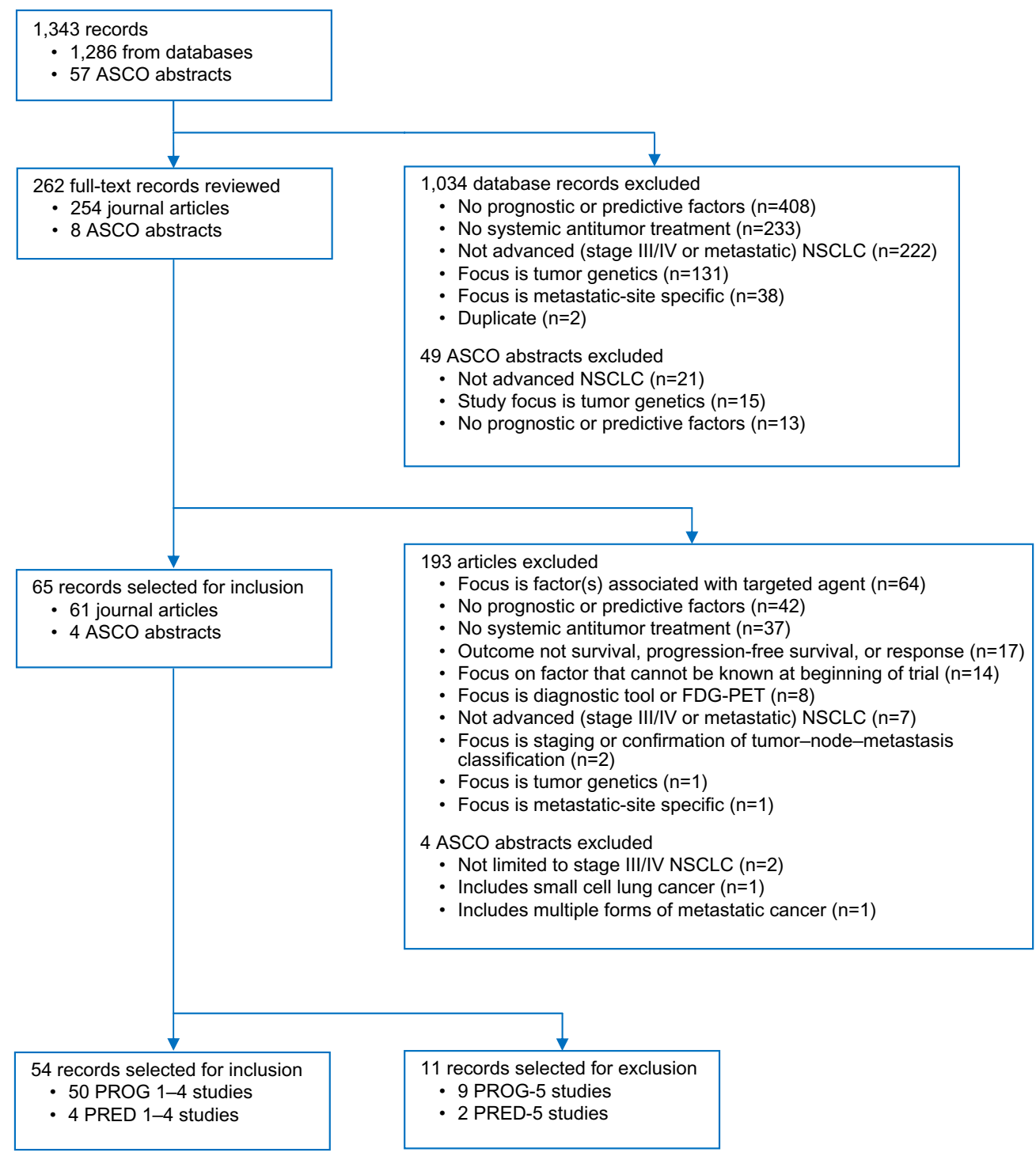

Figure I Flowchart of advanced non-small-cell lung cancer patient heterogeneity reference review.

Note: PROG-I-5 and PRED-I-5 represent a rating system for prognostic and predictive studies, respectively, where one is high and five is low.

Abbreviations: ASCO, American Society of Clinical Oncology; FDG-PET, fluorodeoxyglucose positron emission tomography; NSCLC, non-small-cell lung cancer.

between sex and outcomes, as did 56\% of the nine PROG-2 studies, $38 \%$ of the eight PROG-3 studies, and $20 \%$ of the 15 PROG-4 studies. In all cases, female sex was associated with better outcomes. ${ }^{15,16,19,23-25,28,31,32,35,36,38,42,47,51,54,55}$

Age was most commonly dichotomized using the cutoff of 65 or 70 years. Thirty-nine of the studies examined the relationship between age and survival, with four (10\%) reporting a significant finding. Among the four studies ${ }^{37,40,42,43}$ in which age was a significant prognostic factor, the evidence was inconsistent - older age appeared to be associated with better outcomes in three of the reviewed studies ${ }^{37,40,42}$ and associated with a worse outcome in one reviewed study. ${ }^{43}$

Histology was most frequently dichotomized as adenocarcinoma versus other (nonadenocarcinoma, squamous) or nonsquamous versus squamous. Histology was evaluated in 31 studies and was found to be a significant prognostic factor in five studies $(16 \%)$. Of these five studies ${ }^{15,28,46,52,56}$ that reported a significant association between histology and survival, adenocarcinoma histology appeared to be associated with better outcomes for four of these studies. . $^{15,46,52,56}$

Weight loss was often categorized in the literature by the percentage of body weight lost, although the time frames over which the weight loss occurred were often not well defined. Body mass index (BMI) was also used to classify patients (underweight: $\mathrm{BMI}<18.5$; normal: $18.5 \leq \mathrm{BMI}<25$; overweight: $25 \leq \mathrm{BMI}<30$; obese: $\mathrm{BMI} \geq 30$ ) and to compare different BMI categories. Twenty-one studies assessed weight loss and/or BMI, and eleven studies (52\%) reported 


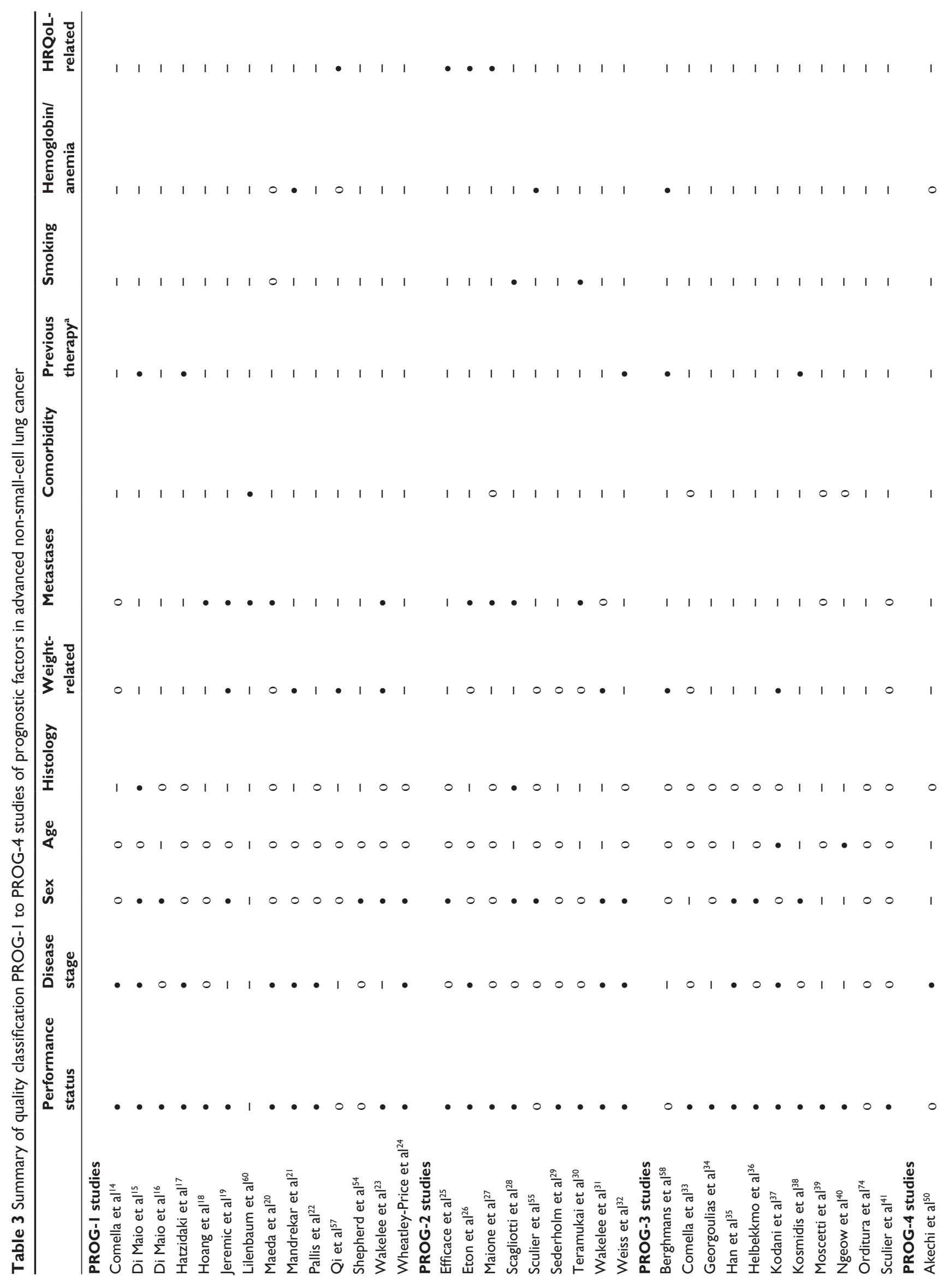




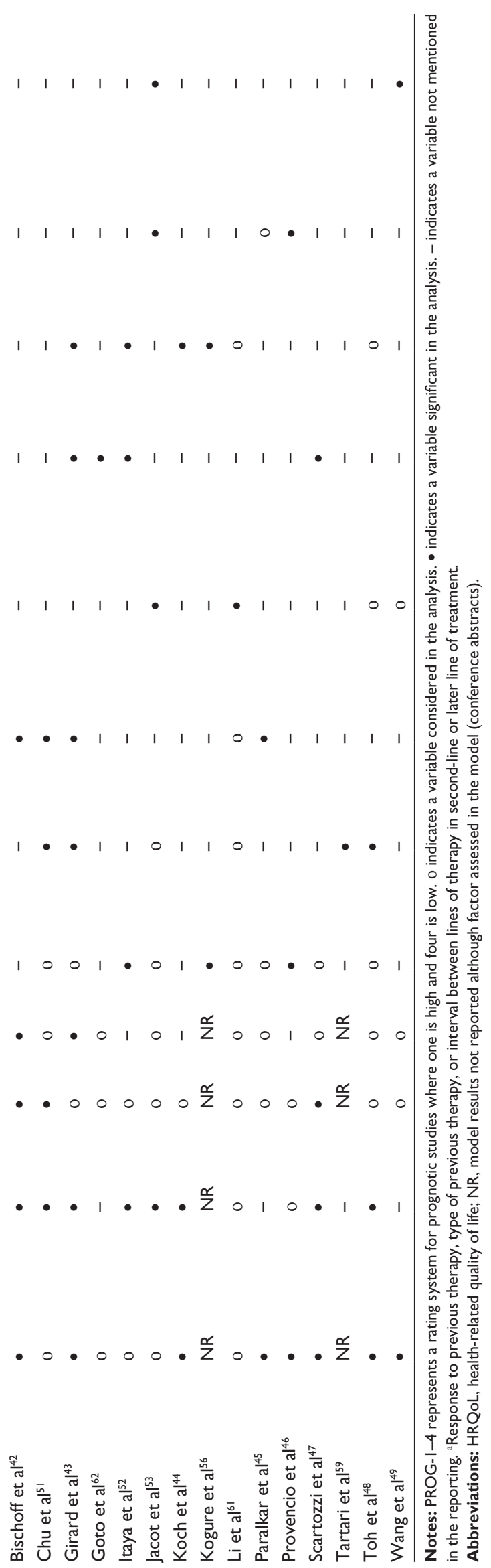

a significant association with survival (four PROG-1 studies, one PROG-2 study, two PROG-3 studies, and four PROG-4 studies). In these studies reporting a significant association, less weight loss or a normal BMI at baseline was associated with better outcomes in all the studies. ${ }^{19,21,23,31,37,43,48,51,57-59}$

Various metastatic features were examined as potential prognostic factors. The presence or extent of metastases was evaluated in 18 studies, and a significant association was identified in 13 (72\%) of the total assessed studies. ${ }^{18-20,23,26-28,30,42,43,45,51,60}$ Seven of the 13 studies assessed the number of metastatic sites, ${ }^{18-20,27,28,42,45}$ and six of these studies found a significant association between a larger number of sites and worse OS or TTP. . $19,19,27,28,42,45$ In addition, six studies assessed the presence of liver metastases, five of which found a significant association between the presence of liver metastases and worse OS. ${ }^{18-20,30,45,51}$ Overall, when a significant association was identified, less extensive metastases were associated with better outcomes in all situations.

In the reviewed studies, comorbidity was defined and categorized by dichotomous groupings of the Charlson Comorbidity Index score, number of comorbid conditions, presence or absence of a specific comorbidity, or dichotomous groupings of the Simplified Comorbidity Score. Comorbidity was evaluated in nine studies, and three of these studies $(33 \%)$ reported a significant association. Of the three studies that reported a significant association, two studies examined the number of comorbid conditions (less than two versus two or more) ${ }^{60,61}$ and one study examined comorbidity as Simplified Comorbidity Score (nine or less versus more than nine) and Charlson Comorbidity Index score (less than three versus three or more). ${ }^{53}$ In the three studies that reported comorbidity as a statistically significant prognostic determinant of response, less comorbidity was associated with better outcomes. . $3,60,61$

Aspects of previous therapy that were examined as potential prognostic factors included type of therapy, response to previous therapy, and interval between firstline and second-line or later therapy. Previous therapy was assessed as a possible prognostic factor in nine studies. Among these studies, eight studies (89\%) that assessed the prognostic significance of previous therapy in patients receiving second-line or later therapy reported statistically significant associations between response to previous treatment and outcomes. ${ }^{15,17,32,43,47,52,58,62}$ One study assessed previous radiotherapy in a first-line advanced NSCLC treatment population and reported that no previous radiotherapy was significantly associated with better survival and TTP. ${ }^{38}$ In the majority of studies assessing response to previous 
$\square$ Associated with better outcome $\square$ Associated with worse outcome $\square$ No statistically significant association found

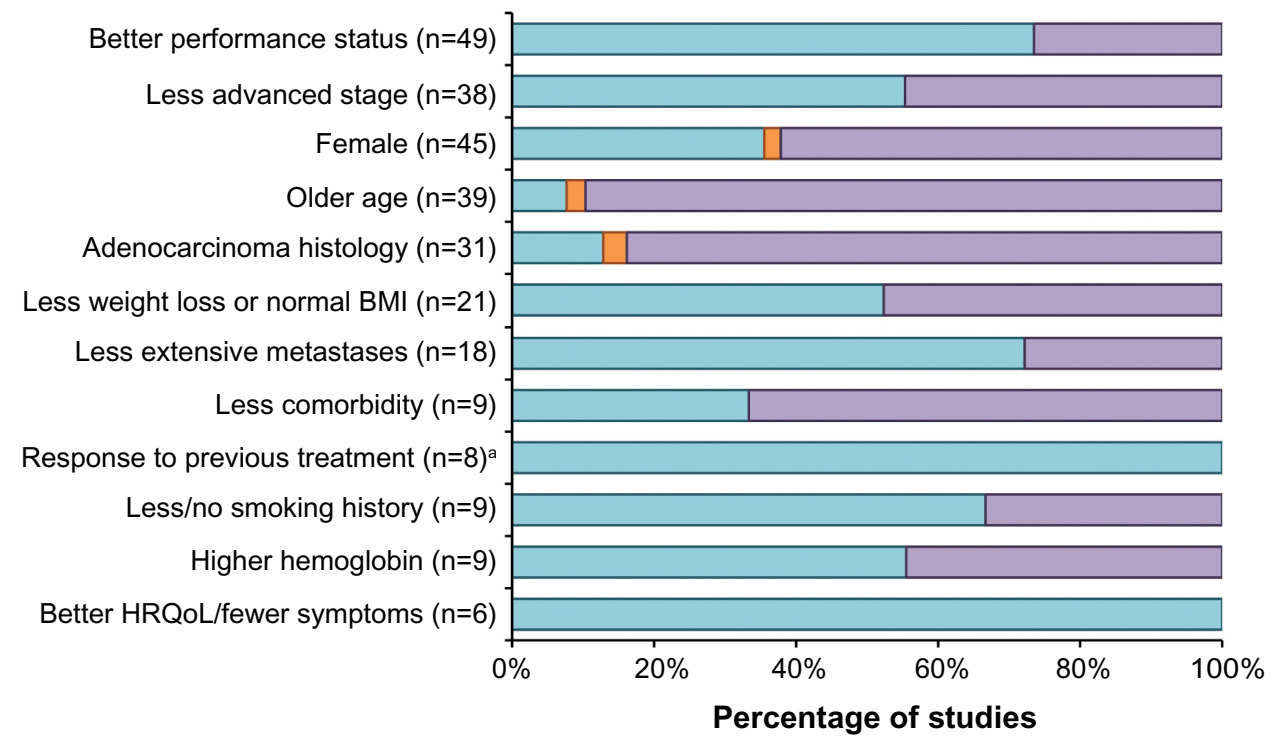

Figure 2 Directional evidence of prognostic factors in advanced non-small-cell lung cancer.

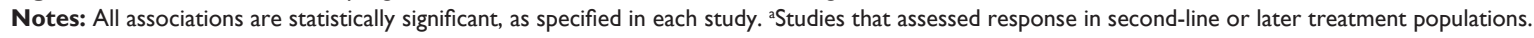
Abbreviations: BMI, body mass index; HRQoL, health-related quality of life.

therapy, responding to prior treatment was associated with better outcomes.

Smoking status was evaluated as a prognostic factor for survival or response in nine of the evaluated studies, with six studies $(67 \%)$ reporting a significant association. Both PROG-2 studies reported a significant association between smoking status and outcomes, as did four of the six PROG-4 studies. Of the studies that found a significant association, less or no smoking was associated with favorable outcomes in all cases. ${ }^{28,30,43,44,52,56}$

Blood hemoglobin concentration was assessed as a potential prognostic factor in nine studies, and five of these studies $(56 \%)$ reported a significant association. All five of these studies found that a higher hemoglobin level was associated with better outcomes..$^{21,46,53,55,58}$ Laboratory values other than hemoglobin were considered as potential prognostic factors in several studies. Explored laboratory values included albumin, alkaline phosphatase, C-reactive protein, lactate dehydrogenase, interleukin-2, and interleukin-10, and several studies assessed multiple laboratory values. Serum albumin was significantly associated with OS (four studies) or PFS (one study), and lower albumin levels were associated with worse outcomes. ${ }^{20,37,45,46,60}$ Lactate dehydrogenase was significantly associated with survival in three studies, with elevated lactate dehydrogenase associated with shorter survival. ${ }^{30,50,60}$ Serum neuron-specific enolase was significantly associated with survival in three studies. ${ }^{20,37,53}$ In two studies, the direction of the association was reported, and in these studies, higher neuron-specific enolase levels were associated with worse survival. ${ }^{20,53}$

Pretreatment HRQoL or patient-reported symptoms were evaluated in six studies and were found to be significant in all six $(100 \%)$ of the studies. In these studies, a variety of assessment tools were used and significant findings were reported for associations between various HRQoL or symptom severity measures and outcomes, including better HRQoL, better physical wellbeing and functioning, and less pain, dysphagia, severe symptoms, and coughing. Of the six studies that reported HRQoL to be a significant prognostic factor, better HRQoL and less symptom burden were associated with better outcomes. ${ }^{25-27,49,53,57}$

\section{Predictive factors}

The distribution of predictive factor studies presented in Tables 4 and 5 summarizes study-specific results for those with significant associations of achieving a specific outcome (ie, PFS, OS, TTP, or RR) when treated with a specific therapy. Overall, ten studies reported information for predictive factors, six studies included both prognostic and predictive factors, ${ }^{28,30,31,41,52,62}$ and four studies focused exclusively on predictive factors. ${ }^{63-66} \mathrm{Of}$ the ten studies that assessed predictive factors, half found no significant results. All four of the exclusively predictive studies were classified as level two (PRED-2), ${ }^{63-66}$ and some of these studies reported on multiple predictive factors, particularly one of the PRED-2 studies. ${ }^{66}$ Overall, two studies reported PS to be a significant predictive 
Table 4 Summary of quality classification for studies of predictive factors in advanced non-small-cell lung cancer

\begin{tabular}{|c|c|c|c|c|c|c|c|c|c|}
\hline & $\begin{array}{l}\text { Performance } \\
\text { status }\end{array}$ & $\begin{array}{l}\text { Disease } \\
\text { stage }\end{array}$ & Sex & Age & Histology & Race & $\begin{array}{l}\text { Previous } \\
\text { therapy }^{\mathrm{a}}\end{array}$ & Smoking & $\begin{array}{l}\text { Laboratory } \\
\text { value variables }\end{array}$ \\
\hline \multicolumn{10}{|l|}{ PRED-2 studies } \\
\hline Ardizzoni et al ${ }^{63}$ & - & - & - & - & - & - & - & - & - \\
\hline Itaya et $\mathrm{a}^{52}$ & - & - & - & - & o & - & - & o & - \\
\hline Obasaju et al ${ }^{64}$ & - & - & - & - & - & o & - & - & - \\
\hline Scagliotti et $\mathrm{al}^{28}$ & - & - & - & - & o & - & - & - & - \\
\hline Soria et $\mathrm{a}^{65}$ & $\bullet b$ & - & - & - & - & - & - & - & o \\
\hline Syrigos et al ${ }^{66}$ & $\bullet$ & - & - & $\bullet$ & $\bullet$ & $\bullet$ & - & $\bullet$ & - \\
\hline Teramukai et $\mathrm{al}^{30}$ & - & - & - & - & - & - & - & - & o \\
\hline \multicolumn{10}{|l|}{ PRED-3 studies } \\
\hline Sculier et $\mathrm{a}^{41}$ & - & - & $\bullet$ & $\bullet$ & - & - & - & - & - \\
\hline Wakelee et $\mathrm{al}^{31}$ & - & - & o & - & - & - & - & - & - \\
\hline \multicolumn{10}{|l|}{ PRED-4 studies } \\
\hline Goto et $\mathrm{a}^{62}$ & - & - & - & - & - & - & - & - & - \\
\hline
\end{tabular}

Notes: PRED-2-4 represents a rating system for predictive studies where two is high and four is low. o indicates a variable considered in the analysis. $\bullet$ indicates a variable

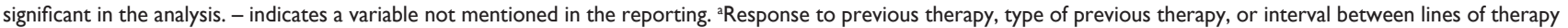
in second-line or later line of treatment. ${ }^{b}$ Borderline significant interaction.

factor (borderline significant in Soria et al's study), ${ }^{65,66}$ two reported age to be significant, ${ }^{41,66}$ one reported disease stage to be significant, ${ }^{66}$ and one reported previous therapy to be significant. ${ }^{62}$ Of the two studies that reported race, one found race to be significant. ${ }^{66}$ One of two studies reported smoking status to be significant, ${ }^{66}$ and one of two studies reported sex to be significant. ${ }^{41}$ Four studies examined histology and two found histology to be significant. ${ }^{63,66}$

\section{Discussion}

This comprehensive review of the published literature was conducted to assess nongenetic prognostic and predictive

Table 5 Summary of statistically significant predictive factor findings in advanced non-small-cell lung cancer

\begin{tabular}{|c|c|c|}
\hline Predictive study & Factor & Conclusion \\
\hline Goto et al ${ }^{62}$ (PRED-4) & $\begin{array}{l}\text { Previous } \\
\text { therapy }\end{array}$ & $\begin{array}{l}\text { Longer time interval between previous therapy and start of DOC was significantly associated with OS. } \\
\text { SD/PD versus CR/PR was significantly associated with response to DOC. }\end{array}$ \\
\hline Sculier et $\mathrm{al}^{41}$ (PRED-3) & Age & $\begin{array}{l}\text { Significant differences not favoring survival with the CIS + CARB + IFOS regimen for women and } \\
\text { patients aged } \geq 60 \text { years. }\end{array}$ \\
\hline Syrigos et $\mathrm{al}^{66}$ (PRED-2) & Age & $\begin{array}{l}\text { In the nonsquamous subgroup analysis, OS for patients aged } \geq 65 \text { years superior in the CIS + PTX } \\
\text { group compared to CIS + GEM group. }\end{array}$ \\
\hline Syrigos et $\mathrm{a}^{66}$ (PRED-2) & $\begin{array}{l}\text { Disease } \\
\text { stage }\end{array}$ & $\begin{array}{l}\text { In the nonsquamous subgroup analysis, OS for stage IIIB was superior in the CIS + PTX group } \\
\text { compared to CIS + GEM group. }\end{array}$ \\
\hline Sculier et a ${ }^{41}$ (PRED-3) & Sex & $\begin{array}{l}\text { Significant differences not favoring survival with the CIS + CARB + IFOS regimen for women and } \\
\text { patients aged } \geq 60 \text { years. }\end{array}$ \\
\hline Ardizzoni et al ${ }^{63}$ (PRED-2) & Histology & $\begin{array}{l}\text { In the meta-analysis, nonsquamous was predictive of lower odds of tumor response and greater risk } \\
\text { of mortality for CARB-containing regimens. }\end{array}$ \\
\hline Syrigos et al ${ }^{66}$ (PRED-2) & Histology & $\begin{array}{l}\text { Histology predicted superior survival for CIS + PTX versus CIS + GEM in patients with nonsquamous } \\
\text { non-small-cell lung cancer and shorter survival for CIS + PTX in patients with squamous cell } \\
\text { carcinoma. The survival advantage for CIS + PTX was maintained across selected patient subgroups } \\
\text { within the nonsquamous group. }\end{array}$ \\
\hline Soria et al ${ }^{65}$ (PRED-2) & PS & $\begin{array}{l}\text { Subgroup analysis showed a survival advantage in PS 0-I patients treated with VIN }+ \text { CIS versus other } \\
\text { treatment regimens. }\end{array}$ \\
\hline Syrigos et al ${ }^{66}$ (PRED-2) & PS & $\begin{array}{l}\text { In the nonsquamous subgroup analysis, OS for PS } 0 \text { versus PS I was superior in the CIS + PTX group } \\
\text { compared with the CIS + GEM group. }\end{array}$ \\
\hline Syrigos et al ${ }^{66}$ (PRED-2) & Race & $\begin{array}{l}\text { In the nonsquamous subgroup analysis, OS for white patients was superior in the CIS + PTX group } \\
\text { versus the CIS + GEM group. }\end{array}$ \\
\hline Syrigos et al ${ }^{66}$ (PRED-2) & Smoking & $\begin{array}{l}\text { In the nonsquamous subgroup analysis, OS for current or former smokers was superior in the CIS + } \\
\text { PTX group as compared with the CIS + GEM group. }\end{array}$ \\
\hline
\end{tabular}

Note: PRED-2-4 represents a rating system for predictive studies where two is high and four is low.

Abbreviations: CARB, carboplatin; CIS, cisplatin; CR, complete response; DOC, docetaxel; GEM, gemcitabine; IFOS, ifosfamide; OS, overall survival; PD, progressive disease; PR, partial response; PS, performance status; PTX, pemetrexed; SD, stable disease; VIN, vinorelbine. 
factors related to heterogeneity of response and outcomes in patients with advanced NSCLC in order to identify subpopulations that experience differential outcomes. This review provides an overview of prognostic and predictive factors assessed over the last decade and complements past literature reviews by providing updated information from studies published since 2000. ${ }^{12,67}$ Both patient- and tumor-related factors that were significantly associated with response or survival were identified.

Patient-related factors (eg, PS, sex, and age) were the most extensively researched prognostic factors, followed by disease stage and histology (both tumor-related variables). Moderately researched prognostic factors were weight-related variables and number or site of metastases, and the least studied nongenetic prognostic factors were comorbidities, previous therapy, smoking status, hemoglobin level, and HRQoL/symptom severity. The prognostic factors with the most consistently demonstrated associations with outcomes were PS, number or site of metastases, previous therapy, smoking status, and HRQoL.

This review demonstrated that better PS (lower Eastern Cooperative Oncology Group PS score or higher KPS score) was prognostic for better outcomes (tumor response or survival) in $73 \%$ of studies evaluating PS, adding to the extensive evidence that supports the prognostic importance of PS across multiple studies, patient populations, and treatments. Clinicians have long regarded PS as a reliable measure of functional independence, and it is a strong prognostic determinant of survival and of the incidence and severity of adverse events, with the majority of Phase III trials stratifying patients according to PS (PS 0/1 versus PS 2). ${ }^{68}$ While this finding is consistent with previous literature, ${ }^{12,67,69}$ it remains remarkable that PS is such a strong factor given the subjective nature of PS measures, the use of different scales, and considerable intraobserver and interobserver variation. Further research might focus on whether the prognostic ability of PS can be improved by using a composite measure with the addition of other nongenetic prognostic factors and by developing more specific standardized criteria.

Of the studies evaluating the following factors, the majority of these studies found that a larger number of metastatic sites and presence of liver metastases were associated with worse survival or TTP, response to previous therapy was prognostic for better outcomes, less or no smoking was prognostic for better survival or response, and better HRQoL was prognostic for better outcomes. The absolute number of studies supporting metastatic features, previous therapy, smoking status, and HRQoL as prognostic factors was limited.
While these prognostic factors consistently demonstrated associations with outcomes, the number of studies with statistically significant associations was low compared to the number of studies evaluating other prognostic factors found in this review. Prognostic values cannot be established by a limited number of studies.

Disease stage is a well-established prognostic factor in NSCLC; ${ }^{12}$ however, only $55 \%$ of the studies in this review assessing disease stage found that less advanced disease was prognostic for patient outcomes (tumor response or survival). Among the studies with the most robust designs, $70 \%$ reported a statistically significant association of disease stage with outcomes. The studies in this review were limited to advanced NSCLC, that is patients' tumors of stage IIIB and stage IV comprise a relatively narrow range within the continuum of tumor staging..$^{70}$ Nonetheless, patients with advanced NSCLC, which usually includes stages IIIB and IV, ${ }^{71}$ generally constitute the population frequently studied in clinical trials.

In a review by Hirsch et al, significant associations between histology and outcomes were observed, and adenocarcinoma was associated with superior survival in patients with advanced NSCLC. ${ }^{67}$ The review by Hirsch et al identified 32 studies that found a statistically significant association between histology and one or more efficacy endpoints. ${ }^{67}$ However, only five of 31 (16\%) prognostic studies identified in the current review found an association between histology and outcomes. In four of the five studies, adenocarcinoma was prognostic for better survival. Two studies included in the current review overlap with studies included in Hirsch et al's review which included studies conducted between 1982 and 2007.

The current review identified only ten studies that evaluated predictive factors, and among these only half reported statistically significant results, with most significant factors occurring in only one or two studies each. Four of the ten studies examined histology, and two of these found histology to be predictive of achieving a specific outcome (ie, PFS, OS, TTP, or RR) when treated with a specific therapy, which supports recent literature findings. ${ }^{67,72,73}$ In the 2007 meta-analysis of nine trials, cisplatin-based chemotherapy prolonged survival versus carboplatin for patients with squamous histology. ${ }^{63}$ A 2010 retrospective analysis of a Phase III randomized controlled trial of 1,725 stage IIIB and IV patients who received first-line therapy (cisplatin plus pemetrexed versus cisplatin plus gemcitabine) confirmed that histology was the only predictive factor of superior survival for cisplatin plus pemetrexed versus 
cisplatin plus gemcitabine in patients with nonsquamous NSCLC and shorter survival for cisplatin plus pemetrexed in patients with squamous cell carcinoma. ${ }^{66}$ Predictive studies for newer targeted therapies, such as EGFR inhibitors and anaplastic lymphoma kinase inhibitors, have focused on selected molecular subgroups of NSCLC and have shown predictive biomarkers for these therapies; however, these studies were not included in this review because the mutations/biomarkers are genetic factors.

One limitation of this review is the heterogeneous nature of the identified studies. The reviewed studies varied in study quality; study populations; statistical analyses; factors included in models and analyses; methods used to define, measure, and classify the factors; laboratory techniques; and treatments received. The classification system reflects that higher ranked prognostic and predictive studies were those with greater internal validity (eg, data analyzed were from randomized controlled trials versus observational studies), with larger versus smaller sample sizes, and with multivariate versus univariate analyses. The reviewed studies were not prospectively designed; they may not be powered to assess statistical significance. Thus, the individual findings of this review should be interpreted in the context of the many factors evaluated. Discrepancies found in the results could reduce the ability to identify the true influence of prognostic and predictive factors. Publication bias may be present because those studies exploring prognostic and predictive factors that did not find significant associations may be less likely to be published. An additional limitation of this review is the time frame captured in this study. Studies published between 2000 and 2010 were reviewed. This could be an important limitation if more recently published studies have found results that are markedly different from those evaluated here.

\section{Conclusion}

This review provides an overview of nongenetic prognostic and predictive factors assessed over the last decade and complements past literature reviews by providing updated information from studies published since 2000. This literature review identified several factors, including PS, number or site of metastases, previous therapy, smoking status, and HRQoL, that may account for HTE and outcomes in advanced NSCLC. The findings in this review that are related to the prognostic ability of these factors generally support current clinical decision making. However, treatment implications of the predictive factors were limited because, for the most part, the interaction of a specific treatment with patient factors was examined in a single study, and only half of the reviewed predictive studies failed to demonstrate significant findings. This comprehensive review of the nongenetic patient factors that have been evaluated in advanced NSCLC can be used to complement information on genetic factors to inform the design of future clinical trials by suggesting additional subgroups of patients with differential treatment response and outcomes.

\section{Acknowledgments}

This study was funded by Eli Lilly and Company. The authors would like to thank Teri Tucker of inVentiv Health Clinical for her editorial contributions and Rebecca McCracken of inVentiv Health Clinical for assistance in preparing the manuscript.

\section{Disclosure}

GCC, AML, KBW, and WJJ are employees and stockholders of Eli Lilly and Company. AMB and JAK report no conflicts of interest in this work.

\section{References}

1. American Cancer Society. Cancer Facts and Figures 2012. Atlanta, GA: American Cancer Society; 2012. Available from: http://www. cancer.org/acs/groups/content/@epidemiologysurveilance/documents/ document/acspc-031941.pdf. Accessed July 29, 2012.

2. Fu JB, Kau TY, Severson RK, Kalemkerian GP. Lung cancer in women: analysis of the national Surveillance, Epidemiology, and End Results database. Chest. 2005;127(3):768-777.

3. Morgensztern D, Waqar S, Subramanian J, Gao F, Govindan R. Improving survival for stage IV non-small cell lung cancer: a Surveillance, Epidemiology, and End Results survey from 1990 to 2005. J Thorac Oncol. 2009;4(12):1524-1529.

4. Alatorre CI, Carter GC, Chen C, et al. A comprehensive review of predictive and prognostic composite factors implicated in the heterogeneity of treatment response and outcome across disease areas. Int J Clin Pract. 2011;65(8):831-847.

5. Sargent DJ, Conley BA, Allegra C, Collette L. Clinical trial designs for predictive marker validation in cancer treatment trials. J Clin Oncol. 2005;23(9):2020-2027.

6. Yip D, Harper PG. Predictive and prognostic factors in small cell lung cancer: current status. Lung Cancer. 2000;28(3):173-185.

7. Fernandez y Garcia E, Nguyen H, Duan N, Gabler NB, Kravitz RL. Assessing heterogeneity of treatment effects: are authors misinterpreting their results? Health Serv Res. 2010;45(1):283-301.

8. Kent DM, Rothwell PM, Ioannidis JP, Altman DG, Hayward RA. Assessing and reporting heterogeneity in treatment effects in clinical trials: a proposal. Trials. 2010;11:85.

9. Gabler NB, Duan N, Liao D, Elmore JG, Ganiats TG, Kravitz RL. Dealing with heterogeneity of treatment effects: is the literature up to the challenge? Trials. 2009;10:43.

10. Mok TS, Wu YL, Thongprasert S, et al. Gefitinib or carboplatinpaclitaxel in pulmonary adenocarcinoma. N Engl J Med. 2009;361(10): 947-957.

11. Maltoni M, Caraceni A, Brunelli C, et al. Prognostic factors in advanced cancer patients: evidence-based clinical recommendations - a study by the Steering Committee of the European Association for Palliative Care. J Clin Oncol. 2005;23(25):6240-6248. 
12. Brundage MD, Davies D, Mackillop WJ. Prognostic factors in nonsmall cell lung cancer: a decade of progress. Chest. 2002;122(3): 1037-1057.

13. Socinski MA, Morris DE, Masters GA, Lilenbaum R. Chemotherapeutic management of stage IV non-small cell lung cancer. Chest. 2003;123(Suppl 1):226S-243S.

14. Comella P, Gambardella A, Frasci G, Avallone A, Costanzo R. Comparison of the safety and efficacy of paclitaxel plus gemcitabine combination in young and elderly patients with locally advanced or metastatic non-small cell lung cancer. A retrospective analysis of the Southern Italy Cooperative Oncology Group trials. Crit Rev Oncol Hematol. 2008;65(2):164-171.

15. Di Maio M, Lama N, Morabito A, et al. Clinical assessment of patients with advanced non-small-cell lung cancer eligible for second-line chemotherapy: a prognostic score from individual data of nine randomized trials. Eur J Cancer. 2010;46(4):735-743.

16. Di Maio M, Morabito A, Barbera S, et al. Education level as prognostic factor of patients (pts) with advanced non-small cell lung cancer (NSCLC) enrolled in clinical trials [abstract]. J Clin Oncol. 2010;28(Suppl 15):abstract 6124.

17. Hatzidaki D, Agelaki S, Mavroudis D, Vlachonikolis I, Alegakis A, Georgoulias V. A retrospective analysis of second-line chemotherapy or best supportive care in patients with advanced-stage non-small-cell lung cancer. Clin Lung Cancer. 2006;8(1):49-55.

18. Hoang T, Xu R, Schiller JH, Bonomi P, Johnson DH. Clinical model to predict survival in chemonaive patients with advanced non-smallcell lung cancer treated with third-generation chemotherapy regimens based on Eastern Cooperative Oncology Group data. J Clin Oncol. 2005;23(1):175-183.

19. Jeremic B, Milicic B, Dagovic A, Aleksandrovic J, Nikolic N. Pretreatment clinical prognostic factors in patients with stage IV nonsmall cell lung cancer (NSCLC) treated with chemotherapy. J Cancer Res Clin Oncol. 2003;129(2):114-122.

20. Maeda T, Ueoka H, Tabata M, et al. Prognostic factors in advanced nonsmall cell lung cancer: elevated serum levels of neuron specific enolase indicate poor prognosis. Jpn J Clin Oncol. 2000;30(12):534-541.

21. Mandrekar SJ, Schild SE, Hillman SL, et al. A prognostic model for advanced stage nonsmall cell lung cancer. Pooled analysis of North Central Cancer Treatment Group trials. Cancer. 2006;107(4): 781-792.

22. Pallis AG, Polyzos A, Boukovinas I, et al. Pooled analysis of elderly patients with non-small cell lung cancer treated with front line docetaxel/gemcitabine regimen: the Hellenic Oncology Research Group experience. J Thorac Oncol. 2008;3(5):505-510.

23. Wakelee HA, Bernardo P, Johnson DH, Schiller JH. Changes in the natural history of nonsmall cell lung cancer (NSCLC) - comparison of outcomes and characteristics in patients with advanced NSCLC entered in Eastern Cooperative Oncology Group trials before and after 1990. Cancer. 2006;106(10):2208-2217.

24. Wheatley-Price P, Blackhall F, Lee SM, et al. The influence of sex and histology on outcomes in non-small-cell lung cancer: a pooled analysis of five randomized trials. Ann Oncol. 2010;21(10): 2023-2028

25. Efficace F, Bottomley A, Smit EF, et al. Is a patient's self-reported health-related quality of life a prognostic factor for survival in nonsmall-cell lung cancer patients? A multivariate analysis of prognostic factors of EORTC study 08975. Ann Oncol. 2006;17(11):1698-1704.

26. Eton DT, Fairclough DL, Cella D, Yount SE, Bonomi P, Johnson DH. Early change in patient-reported health during lung cancer chemotherapy predicts clinical outcomes beyond those predicted by baseline report: results from Eastern Cooperative Oncology Group Study 5592. J Clin Oncol. 2003;21(8):1536-1543.

27. Maione P, Perrone F, Gallo C, et al. Pretreatment quality of life and functional status assessment significantly predict survival of elderly patients with advanced non-small-cell lung cancer receiving chemotherapy: a prognostic analysis of the multicenter Italian lung cancer in the elderly study. J Clin Oncol. 2005;23(28):6865-6872.
28. Scagliotti GV, De Marinis F, Rinaldi M, et al. The role of histology with common first-line regimens for advanced non-small cell lung cancer: a brief report of the retrospective analysis of a three-arm randomized trial. J Thorac Oncol. 2009;4(12):1568-1571.

29. Sederholm C, Hillerdal G, Lamberg K, et al. Phase III trial of gemcitabine plus carboplatin versus single-agent gemcitabine in the treatment of locally advanced or metastatic non-small-cell lung cancer: the Swedish Lung Cancer Study Group. J Clin Oncol. 2005;23(33):8380-8388.

30. Teramukai S, Kitano T, Kishida Y, et al. Pretreatment neutrophil count as an independent prognostic factor in advanced non-small-cell lung cancer: an analysis of Japan Multinational Trial Organization LC00-03. Eur J Cancer. 2009;45(11):1950-1958.

31. Wakelee HA, Wang W, Schiller JH, et al. Survival differences by sex for patients with advanced non-small cell lung cancer on Eastern Cooperative Oncology Group trial 1594. J Thorac Oncol. 2006;1(5):441-446.

32. Weiss GJ, Rosell R, Fossella F, et al. The impact of induction chemotherapy on the outcome of second-line therapy with pemetrexed or docetaxel in patients with advanced non-small-cell lung cancer. Ann Oncol. 2007;18(3):453-460.

33. Comella P, Frasci G, Carnicelli P, et al. Gemcitabine with either paclitaxel or vinorelbine vs paclitaxel or gemcitabine alone for elderly or unfit advanced non-small-cell lung cancer patients. Br J Cancer. 2004;91(3):489-497.

34. Georgoulias V, Agelidou A, Syrigos K, et al. Second-line treatment with irinotecan plus cisplatin vs cisplatin of patients with advanced nonsmall-cell lung cancer pretreated with taxanes and gemcitabine: a multicenter randomized Phase II study. Br J Cancer. 2005;93(7):763-769.

35. Han JY, Lim HS, Lee DH, et al. Randomized Phase II study of two opposite administration sequences of irinotecan and cisplatin in patients with advanced nonsmall cell lung carcinoma. Cancer. 2006;106(4): 873-880.

36. Helbekkmo N, Aasebo U, Sundstrom SH, von Plessen C, Brunsvig PF, Bremnes RM. Treatment outcome in performance status two advanced NSCLC patients administered platinum-based combination chemotherapy. Lung Cancer. 2008;62(2):253-260.

37. Kodani T, Ueoka H, Kiura K, et al. A Phase III randomized trial comparing vindesine and cisplatin with or without ifosfamide in patients with advanced non-small-cell lung cancer: long-term follow-up results and analysis of prognostic factors. Lung Cancer. 2002;36(3):313-319.

38. Kosmidis P, Mylonakis N, Skarlos D, et al. Paclitaxel $\left(175 \mathrm{mg} / \mathrm{m}^{2}\right)$ plus carboplatin $(6 \mathrm{AUC})$ versus paclitaxel $\left(225 \mathrm{mg} / \mathrm{m}^{2}\right)$ plus carboplatin (6 AUC) in advanced non-small-cell lung cancer (NSCLC): a multicenter randomized trial. Hellenic Cooperative Oncology Group (HeCOG). Ann Oncol. 2000;11(7):799-805.

39. Moscetti L, Nelli F, Padalino D, Sperduti I, Giannarelli D, Pollera CF. Gemcitabine and cisplatin in the treatment of elderly patients with advanced non-small cell lung cancer: impact of comorbidities on safety and efficacy outcome. J Chemother. 2005;17(6):685-692.

40. Ngeow J, Leong SS, Gao F, et al. Impact of comorbidities on clinical outcomes in non-small cell lung cancer patients who are elderly and/ or have poor performance status. Crit Rev Oncol Hematol. 2010;76(1): 53-60.

41. Sculier JP, Lafitte JJ, Lecomte J, et al. A three-arm Phase III randomized trial comparing combinations of platinum derivatives, ifosfamide, and/or gemcitabine in stage IV non-small-cell lung cancer. Ann Oncol. 2002;13(6):874-882.

42. Bischoff HG, van den Borne B, Pimentel FL, et al. Observation of the treatment and outcomes of patients receiving chemotherapy for advanced NSCLC in Europe (ACTION study). Curr Med Res Opin. 2010;26(6):1461-1470.

43. Girard N, Jacoulet P, Gainet M, et al. Third-line chemotherapy in advanced non-small cell lung cancer: identifying the candidates for routine practice. J Thorac Oncol. 2009;4(12):1544-1549.

44. Koch A, Fohlin H, Sorenson S. Prognostic significance of C-reactive protein and smoking in patients with advanced non-small cell lung cancer treated with first-line palliative chemotherapy. J Thorac Oncol. 2009;4(3):326-332. 
45. Paralkar VR, Li T, Langer CJ. Population characteristics and prognostic factors in metastatic non-small-cell lung cancer: a Fox Chase Cancer Center retrospective. Clin Lung Cancer. 2008;9(2):116-121.

46. Provencio M, Cobo M, Vazquez-Estevez S, et al. Analysis of prognostic factors in patients with advanced non-small cell lung cancer (NSCLC) who are candidates to receive a second-line treatment [abstract]. J Clin Oncol. 2010;28(suppl 15):abstract e18109.

47. Scartozzi M, Mazzanti P, Giampieri R, et al. Clinical predictive factors for advanced non-small cell lung cancer (NSCLC) patients receiving third-line therapy: selecting the unselectable? Lung Cancer. 2010;68(3):433-437.

48. Toh CK, Wong EH, Lim WT, et al. The impact of smoking status on the behavior and survival outcome of patients with advanced non-small cell lung cancer: a retrospective analysis. Chest. 2004;126(6):1750-1756.

49. Wang XS, Shi Q, Lu C, et al. Prognostic value of symptom burden for overall survival in patients receiving chemotherapy for advanced nonsmall cell lung cancer. Cancer. 2010;116(1):137-145.

50. Akechi T, Okamura H, Okuyama T, Furukawa TA, Nishiwaki Y, Uchitomi Y. Psychosocial factors and survival after diagnosis of inoperable non-small cell lung cancer. Psychooncology. 2009;18(1):23-29.

51. Chu DT, Kim SW, Hsu HK, et al. Patient attitudes towards chemotherapy and survival: a prospective observational study in advanced non-small cell lung cancer. Lung Cancer. 2009;66(2):250-256.

52. Itaya T, Yamaoto N, Ando M, et al. Influence of histological type, smoking history, and chemotherapy on survival after first-line therapy in patients with advanced non-small cell lung cancer. Cancer Sci. 2007;98(2):226-230.

53. Jacot W, Colinet B, Bertrand D, et al. Quality of life and comorbidity score as prognostic determinants in non-small-cell lung cancer patients Ann Oncol. 2008;19(8):1458-1464.

54. Shepherd FA, Abratt R, Crino L, et al. The influence of gemcitabine and cisplatin schedule on response and survival in advanced non-small cell lung cancer. Lung Cancer. 2000;30(2):117-125.

55. Sculier JP, Lafitte JJ, Lecomte J, et al. A Phase III randomized trial comparing sequential chemotherapy using cisplatin-based regimen and paclitaxel to cisplatin-based chemotherapy alone in advanced non-small-cell lung cancer. Ann Oncol. 2007;18(6):1037-1042.

56. Kogure Y, Ando M, Chiba Y, et al. Impact of histology and smoking status on survival outcome of patients with advanced non-small cell lung cancer (NSCLC): West Japan Oncology Group (WJOG) study 3906L [abstract]. J Clin Oncol. 2010;28(Suppl 15):abstract e18013.

57. Qi Y, Schild SE, Mandrekar SJ, et al. Pretreatment quality of life is an independent prognostic factor for overall survival in patients with advanced stage non-small cell lung cancer. J Thorac Oncol. 2009;4(9): 1075-1082.

58. Berghmans T, Lafitte JJ, Lecomte J, et al. Second-line paclitaxel in non-small cell lung cancer initially treated with cisplatin: a study by the European Lung Cancer Working Party. Br J Cancer. 2007;96(11): 1644-1649.

59. Tartari RF, Abreu Nunes C, Moreira J, et al. The mid-arm muscle circumference measurement and the prognosis of stage IV non-small cell lung cancer patients [abstract]. J Clin Oncol. 2010;28(Suppl 15):abstract e18058.
60. Lilenbaum R, Villaflor VM, Langer C, et al. Single-agent versus combination chemotherapy in patients with advanced non-small cell lung cancer and a performance status of two: prognostic factors and treatment selection based on two large randomized clinical trials. J Thorac Oncol. 2009;4(7):869-874.

61. Li J, Chen P, Dai CH, Li XQ, Bao QL. Prognostic factors in elderly patients with advanced non-small cell lung cancer treated with chemotherapy. Oncology. 2009;76(5):355-362.

62. Goto Y, Sekine I, Yamada K, et al. Influence of previous chemotherapy on the efficacy of subsequent docetaxel therapy in advanced non-small cell lung cancer patients. J Thorac Oncol. 2008;3(4):412-416.

63. Ardizzoni A, Boni L, Tiseo M, et al. Cisplatin- versus carboplatin-based chemotherapy in first-line treatment of advanced non-small-cell lung cancer: an individual patient data meta-analysis. J Natl Cancer Inst. 2007;99(11):847-857.

64. Obasaju CK, Ansari RH, Socinski MA, et al. A comparison of white and African American outcomes from a three-arm, randomized, Phase III multicenter trial of advanced or metastatic non-small cell lung cancer. J Thorac Oncol. 2010;5(7):993-1000.

65. Soria JC, Brisgand D, Le Chevalier T. Do all patients with advanced non-small-cell lung cancer benefit from cisplatin-based combination therapy? Ann Oncol. 2001;12(12):1667-1670.

66. Syrigos KN, Vansteenkiste J, Parikh P, et al. Prognostic and predictive factors in a randomized Phase III trial comparing cisplatin-pemetrexed versus cisplatin-gemcitabine in advanced non-small-cell lung cancer. Ann Oncol. 2010;21(3):556-561.

67. Hirsch FR, Spreafico A, Novello S, Wood MD, Simms L, Papotti M. The prognostic and predictive role of histology in advanced non-small cell lung cancer: a literature review. J Thorac Oncol. 2008;3(12): $1468-1481$

68. Gebbia V, Galetta D, De Marinis F. Non small cell lung cancer patients with ECOG PS2: unsolved questions and lessons from clinical trials. Ann Oncol. 2005;16(Suppl 4):iv123-iv131.

69. Berghmans T, Paesmans M, Sculier JP. Prognostic factors in stage III non-small cell lung cancer: a review of conventional, metabolic, and new biological variables. Ther Adv Med Oncol. 2011;3(3):127-138.

70. Jemal A, Siegel R, Ward E, et al. Cancer statistics, 2008. CA Cancer J Clin. 2008;58(2):71-96.

71. Edge SB, Byrd DR, Compton CC, Fritz AG, Greene FL, Trotti A, editors AJCC Cancer Staging Manual. 7th ed. New York, NY: Springer;2010.

72. Scagliotti G, Brodowicz T, Shepherd F, et al. Treatment-by-histology interaction analyses in three Phase III trials show superiority of pemetrexed in nonsquamous non-small cell lung cancer. JThorac Oncol. 2011;6(1):64-70.

73. Sandler A, Yi J, Dahlberg S, et al. Treatment outcomes by tumor histology in Eastern Cooperative Group Study E4599 of bevacizumab with paclitaxel/carboplatin for advanced non-small cell lung cancer. J Thorac Oncol. 2010;5(9):1416-1423.

74. Orditura M, Romano C, De Vita F, et al. Behavior of interleukin-2 serum levels in advanced non-small-cell lung cancer patients: relationship with response to therapy and survival. Cancer Immunol Immunother. 2000;49(10):530-536
Cancer Management and Research

\section{Publish your work in this journal}

Cancer Management and Research is an international, peer-reviewed open access journal focusing on cancer research and the optimal use of preventative and integrated treatment interventions to achieve improved outcomes, enhanced survival and quality of life for the cancer patient The journal welcomes original research, clinical \& epidemiological

\section{Dovepress}

studies, reviews \& evaluations, guidelines, expert opinion \& commentary, case reports \& extended reports. The manuscript management system is completely online and includes a very quick and fair peerreview system, which is all easy to use. Visit http://www.dovepress.com/ testimonials.php to read real quotes from published authors. 